\title{
Extensão nas redes sociais: teria a pandemia mudado os hábitos da comunidade?
}

\author{
Extension on social medias: has the pandemic \\ changed the community habits?
}

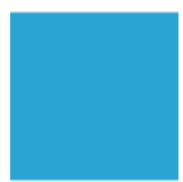

Revista Extensão em Foco
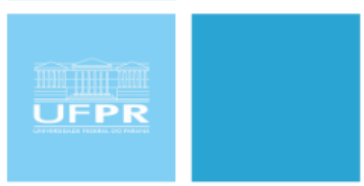

ISSN $2358-7180$

\section{Camila Burigo Marin', Tainara Angela Piran Zanatta ${ }^{2}$, Ursula Lima Tatit ${ }^{3}$, Rafaela Picolotto ${ }^{4}$}

\section{RESUMO}

Com a pandemia ocasionada pelo SARS CoV-2, o isolamento social tornou-se primordial em diversos lugares. Novos hábitos em relação a forma e frequência de consumo surgiram modificando o modo de viver. Como reflexo do isolamento social, as intervenções do projeto de extensão Água Viva: Do Recurso ao Patrimônio, passaram a acontecer integralmente online. Este movimento gerou uma aproximação dos seguidores que manifestaram maior interesse por hábitos mais sustentáveis. Realizouse a aplicação de um questionário semi-estruturado com os seguidores do projeto, com o intuito de averiguar o comportamento dos mesmos durante a pandemia, conhecê-los melhor e poder direcionar a produção de conteúdo nas redes sociais. Participaram 215 pessoas de 18 países, que responderam questões sobre segregação e destinação de resíduos, e o consumo de produtos potencialmente impactantes para a poluição plástica. Os resultados mostraram que, segundo a percepção dos entrevistados, houve um aumento na produção de resíduos durante a pandemia (produção de macroplásticos), bem como um aumento na frequência na lavagem de roupas (produção de microplásticos). Em contrapartida, o público entrevistado passou a utilizar menos o serviço de entregas, especialmente de alimentos prontos, durante a primeira fase da pandemia e relataram se preocupar com o tipo de embalagem disponibilizadas por esses serviços (73\%), uma vez que mais de $50 \%$ dos pedidos vem em plástico ou em material misturado contendo plástico. Apesar das dificuldades relatadas pelos participantes em ter uma vida mais sustentável, 99\% dos participantes afirmaram estar dispostos a mudar seus hábitos em prol de um desenvolvimento sustentável.

Palavras-chave: Coronavírus. Resíduos sólidos. Polímeros. Redes sociais. Meio ambiente.

\section{ABSTRACT}

With the pandemic caused by the SARS CoV-2, social isolation has become essential in several places. New habits concerning the form and frequency of consumption have emerged, changing the way we live. As a reflection of social isolation, the interventions of Água Viva: Do recurso ao patrimônio extension project, started to happen entirely online. This movement created an approximation with the followers, who expressed interest in more sustainable habits. Based on this, a semi-structured questionnaire was applied with the followers of the project. 215 people from 18 countries participated in the interview, answering questions about segregation and destination of waste and the consumption

1 Doutora. Universidade do Vale do Itajaí (UNIVALI), Itajaí, Santa Catarina, Brasil. E-mail: milaoceano@gmail.com Orcid: https://orcid.org/0000-0002-3901-0033

${ }^{2}$ Acadêmica do curso de Oceanografia. Universidade do Vale do Itajaí (UNIVALI), Itajaí, Santa Catarina, Brasil. E-mail: tainaraponey@gmail.com Orcid: https://orcid.org/0000-0003-0126-5935

${ }^{3}$ Acadêmica do curso de Oceanografia. Universidade do Vale do Itajaí (UNIVALI), Itajaí, Santa Catarina, Brasil E-mail: urstatit@gmail.com Orcid: https://orcid.org/0000-0001-6891-4421

4 Mestra. Universidade do Vale do Itajaí (UNIVALI), Itajaí, Santa Catarina, Brasil. E-mail: rafaelapicolotto@gmail.com Orcid: https://orcid.org/0000-0001-8651-1984 
of products potentially contributing to plastic pollution. The results presented that there was an increase in the production of waste during the pandemic (microplastic production), as well as an increase in the frequency of washing clothes. On the other hand, the public interviewed started to use the delivery service less during a pandemic and reported being concerned with the type of packaging provided by these services $(73 \%)$, since more than $50 \%$ of the orders come in plastic or mixed material containing plastic. Despite the difficulties reported by the participants in having a more sustainable life, the most surprising result was that $99 \%$ of the participants stated that they were willing to change their habits in favor of sustainable development.

Keywords: Coronavirus; Solid waste. Polymers. Social media. Environment.

\section{INTRODUÇÃO}

Desde o início da civilização, o ser humano gradualmente começou a manipular a natureza para seu próprio benefício, o desejo de conduzir a natureza de acordo com suas necessidades e caprichos, acabaram por impactar a mesma de várias maneiras (PRAKASH; SRIVASTAVA, 2020). O afastamento do ser humano da natureza gera consequências indiretas e diretas, tais como as mudanças climáticas que propiciam a veiculação de muitas doenças, a introdução de novas pragas e patógenos em novas regiões ou comunidades, ou ainda a poluição ambiental, que por sua vez, tem o potencial de mudar a distribuição e carga de várias doenças infecciosas incluindo doenças bacterianas e virais (PRAKASH, 2020).

A pandemia ocasionada pelo vírus SARS CoV-2, também conhecido como coronavírus, está sendo considerada a calamidade mais importante do século (NEHER et. al, 2020). Até o início de dezembro ocasionou mais de 72 milhões de casos confirmados de infecção e levou à óbito mais de 1,6 milhão de pessoas (ONU, 2020). Além dos números assustadores a pandemia trouxe diversas mudanças no dia a dia das pessoas em diferentes partes do mundo. $\mathrm{O}$ isolamento social, necessário para que o vírus não se dissemine, fez com que uma nova rotina surgisse acompanhada de novos hábitos.

De um lado, tem-se benefícios com isolamento social, como por exemplo, a queda dos níveis de poluição do ar e da água em várias regiões do globo (PRAKASH; SRIVASTAVA, 2020), por outro lado, gera efeitos que causam preocupação como o aumento da geração de resíduos sólidos em decorrência do aumento do consumo (NZEADIBE; EJIKE-ALIEJI, 2020).

Estimativas da Associação Brasileira de Empresas de Limpeza Pública e Resíduos Especiais, mostram que as medidas de isolamento social fizeram com que a quantidade de resíduos residenciais aumentasse, especialmente a produção de recicláveis, que aumentou em torno de $25 \%$ no Brasil. Porém a reciclagem destes materiais não aumentou na mesma proporção e além disso, o setor em diversos momentos parou ou reduziu a intensidade de suas atividades (ABRELPE, 2020). Não só a produção de resíduos recicláveis, mas também o 
consumo de água residencial aumentou, seja pelo fato de as pessoas passarem mais tempo em casa, mas também devido às novas medidas sanitizantes, que aumentou a frequência da lavagem de mãos, banhos e higienização de roupas e materiais (COOPER, 2020).

Dentre esses novos hábitos no Brasil, pode-se ainda destacar a suspensão dos transportes coletivos, migração de algumas empresas para o modo "home office" e migração de algumas escolas e universidades para o ambiente virtual. Essas mudanças não impactaram apenas o dia a dia da população, mas também a continuidade de diversos projetos, como os de extensão universitária.

De acordo com Nunes e da Cruz Silva (2011), a extensão universitária funciona como uma via de mão dupla em que a universidade leva conhecimentos e/ou assistência à comunidade e recebe dela influxos positivos, tais como suas reais necessidades, anseios e aspirações, essa parceria enriquece o conhecimento acadêmico e ao mesmo tempo possibilita melhores condições para a comunidade participante, quebrando a barreira entre academia e a comunidade. Aliada a extensão universitária, a educação ambiental possibilita o desenvolvimento de trabalhos em diversas áreas do conhecimento e impulsiona a conscientização sobre o agravamento de problemas ambientais gerados pela sociedade atual (GRZEBIELUKA; KUBIAK; SCHILLER, 2014), trazendo à luz suas causas, consequências e soluções.

Segundo a UNEP (2018) um dos maiores desafios ambientais da atualidade refere-se ao uso do plástico, por ser um material de baixo custo, resistente e com inúmeras aplicações, entrou de forma rápida na vida de milhares de pessoas, à primeira vista facilitando tarefas diárias, porém a produção de plástico continua crescendo e consequentemente a geração deste tipo de resíduo também, que se acumulam nos mais diversos ambientes naturais, causando risco a flora e fauna do planeta. $\mathrm{O}$ aumento da utilização e descarte desses materiais durante a pandemia ocasionada pelo SARS CoV-2, pode trazer impactos ambientais e sociais ainda maiores (FAGUNDES; MISSIO, 2019).

O projeto de extensão Água Viva: Do Recurso ao Patrimônio, vem trabalhando a temática da poluição marinha desde 2015 em suas atividades de extensão. Durante a pandemia ajustou suas atividades para uma maior atuação via redes sociais, outrora utilizadas apenas para divulgação do trabalho.

A internet pode ser considerada uma excelente ferramenta na realização de atividades extensionistas e de ensino, devido ao amplo potencial na divulgação de informações e ao interesse que desperta (CALIMAN FILADELFI et al., 2019), e também pode ser utilizada para 
uma aproximação da comunidade, especialmente quando não é possível atingi-las pessoalmente.

A página do projeto Água Viva promoveu em julho de 2020, o movimento julho sem plástico em suas redes sociais (instagram e facebook), onde diversas pessoas participaram ativamente demonstrando preocupação e vontade de mudar. A partir da observação dos diferentes hábitos e dos relatos do público do projeto nas redes sociais, surgiu a ideia de aplicar um questionário online, buscando compreender como as pessoas estão se comportando em termos de produção e segregação de resíduos, consumo e usos de materiais plásticos no seu cotidiano e possíveis mudanças durante a pandemia.

\section{MÉTODOS}

O projeto Água Viva atua desde 2015 junto a comunidade do litoral centro-norte catarinense, embora tenha suas redes sociais desde o princípio, apenas em 2018 começou a utilizar suas redes não apenas para a divulgação do projeto, mas também para a veiculação de materiais educativos sobre poluição e sustentabilidade.

Visto a grande discussão nas redes sociais do projeto Água Viva, seus seguidores foram estimulados a responder um questionário online semiestruturado para avaliação da percepção e compreensão do público-alvo do projeto a respeito dos hábitos e produção de resíduos sólidos no âmbito de cada residência. Os questionários foram preenchidos de forma espontânea pelos seguidores do projeto, sendo que não era necessário se identificar para o preenchimento do mesmo. As perguntas norteadoras abordavam questões como o consumo de alimento e outros suprimentos entregues em casa ou comprados diretamente no mercado, o tipo de embalagem destes produtos, a frequência de consumo, a segregação dos resíduos na hora do descarte, utilização de máscaras descartáveis e reutilizáveis, consumo de produtos que contêm ou não plástico em sua formulação/embalagem. Todas as entrevistas foram salvas em formato Excel® e posteriormente analisadas qualiquantitativamente (BARDIN, 2016).

\section{RESULTADOS E DISCUSSÃO}

\section{Perfil dos entrevistados}

Foram entrevistadas 215 pessoas que acompanham o projeto, entre os quais 182 brasileiros, sete representantes da Índia, cinco em Portugal, quatro na Espanha, dois na Irlanda, dois em Taiwan e um representante de cada um dos seguintes países: Austrália, Áustria, Egito, 
Estados Unidos, Bélgica, Grécia, Guatemala, Lituânia, Turquia e Inglaterra. A maior parte dos entrevistados eram do sexo feminino (71,6\%), o sexo masculino representou $27,9 \%$ dos entrevistados e apenas um entrevistado não quis informar o seu gênero (Figura 1).

Figura 1 - Perfil dos entrevistados pelo projeto Água Viva: Do Recurso ao Patrimônio
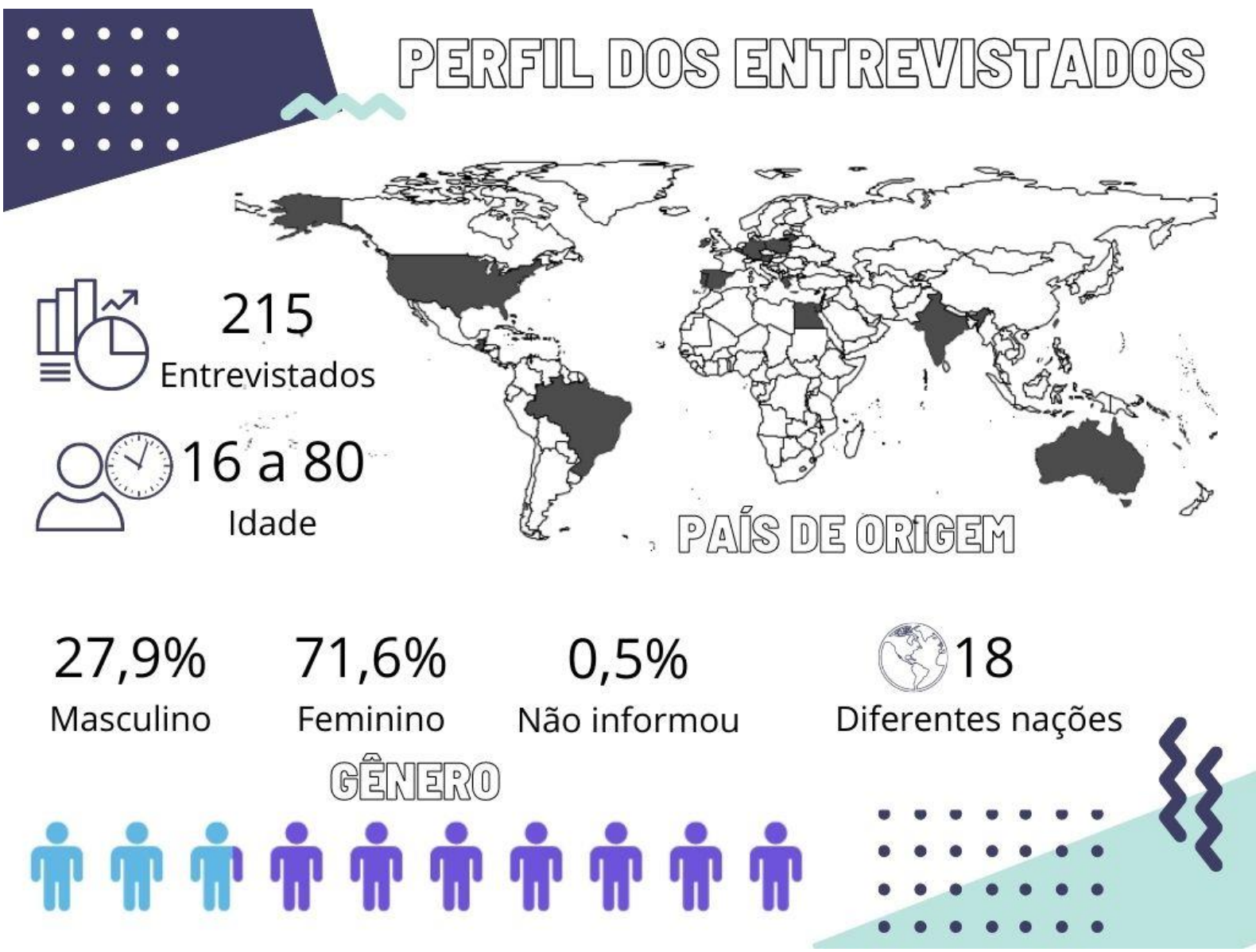

Fonte: Autoria própria (2020).

\section{Produção, segregação e destinação dos resíduos}

O aumento da quantidade de resíduos sólidos é um grave problema ambiental (ANDREOLI et al., 2014). Em 2018, o Brasil gerou 79 milhões de toneladas de resíduos sólidos e apenas 72,7 milhões foram coletados. Desses 72,7 milhões, apenas 59,5\% tiveram destinação em aterros sanitários enquanto $40,5 \%$ foram depositados em locais inadequados tais como lixões e aterros controlados (ABRELPE, 2019) expondo a população aos perigos da poluição.

O planeta terra é um sistema fechado, não existe fora do ponto de vista do planeta. Para a produção de cada bem ou serviço são consumidos recursos naturais que podem ter uma vida útil maior se consumirmos menos, reaproveitarmos e reciclarmos mais (ANDREOLI, et al., 2014). Ao evitar o desperdício, poupamos também água, energia e reduzimos as emissões de 
gases de efeito estufa na fabricação de novos produtos e na disposição dos mesmos (HOORNWEG; BHADA-TATA, 2012).

Figura 2 - Tipo de segregação e destinação dos resíduos utilizada pelo público (reciclável, rejeito, compostável), a frequência e volume de descarte durante a pandemia.
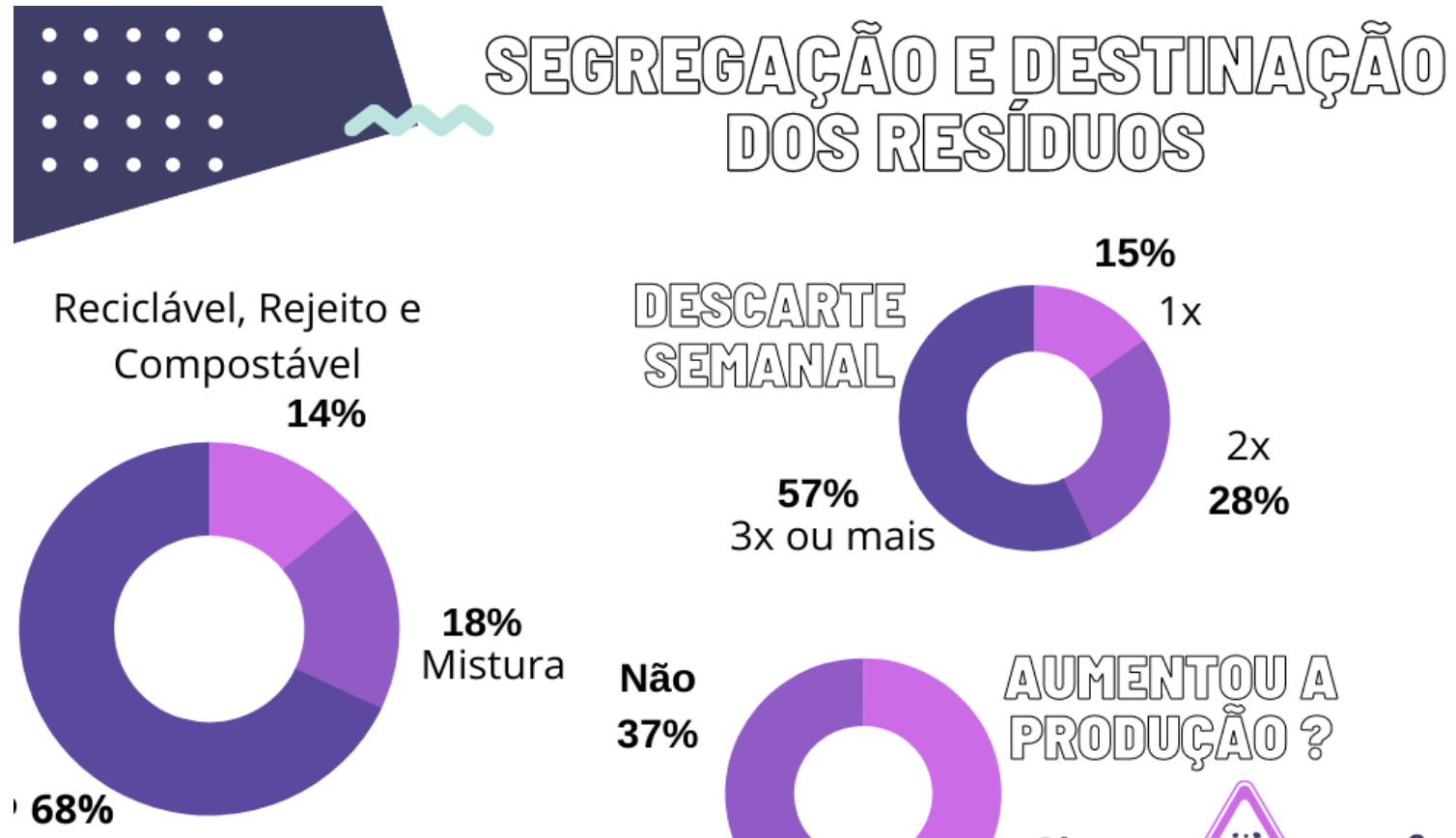

Reciclável e Rejeito
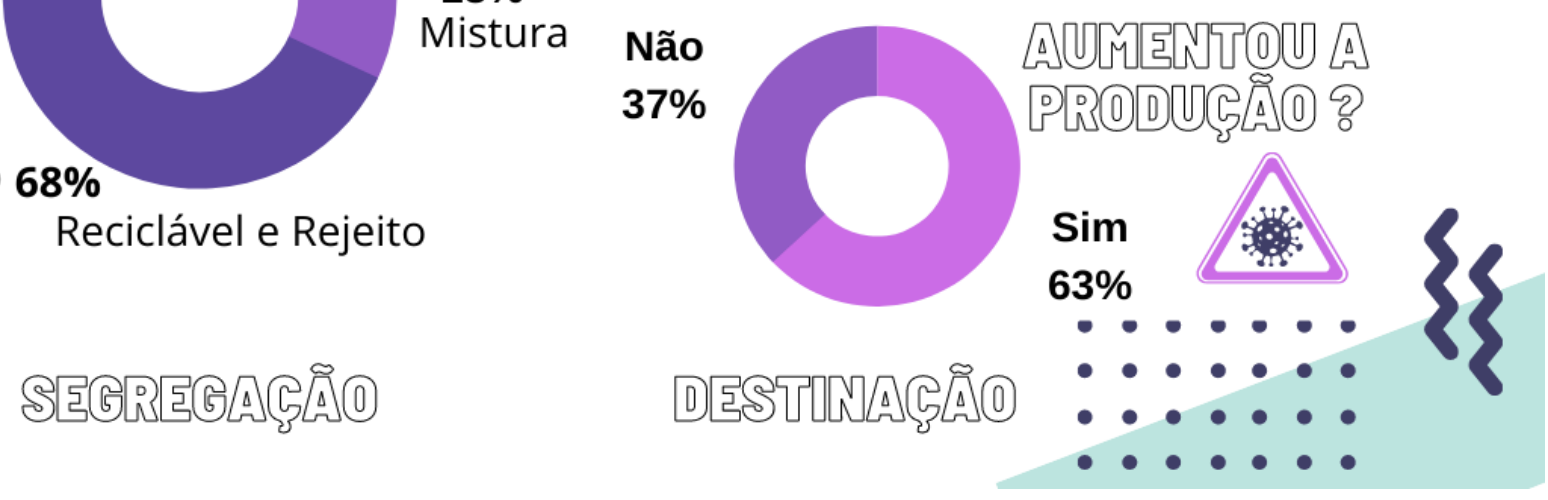

Fonte: Autoria própria (2020).

Sobre a segregação dos resíduos em suas casas (Figura 2), aproximadamente $68 \%$ dos participantes responderam que separam entre rejeito e reciclável, 14\% disseram separar em rejeito, reciclável e compostável e 18\% disseram não separar, acumulando todos os tipos de resíduos na mesma sacola para posterior descarte. Cabe destacar que a separação torna-se necessária pois cada resíduo possui destino diferente, sendo que rejeitos (o que costuma-se chamar de orgânico além dos resíduos oriundos dos sanitários) devem ser destinados para o aterro sanitário, recicláveis para cooperativas de triagem e os orgânicos (restos de alimentos) para a compostagem.

Alguns participantes que separam seus resíduos recicláveis, informaram estar guardando/acumulando latas de alumínio, para doar a catadores de material reciclável de sua cidade. Em relação a produção de rejeitos, alguns relataram sobre iniciativas para redução dos 
rejeitos, através de uma nova abordagem com os resíduos orgânicos, implementando o uso de composteiras caseiras e aproveitando melhor os alimentos. Foram citados o aproveitamento do uso da casca do abacaxi para fazer suco e chá, a casca da banana para fazer refogada e outras formas de aproveitar os alimentos na sua integralidade.

Quando perguntado sobre a frequência semanal do descarte de resíduos (Figura 2), 15\% dos participantes responderam fazer o descarte uma vez na semana, 28\% duas vezes na semana, $34 \%$ três vezes na semana e $23 \%$ dos entrevistados mais de três vezes na semana. Sobre a produção de resíduos residenciais, 63\% relataram um aumento na produção. Esse aumento na produção de resíduos pode estar atrelado a uma modalidade empregatícia que ficou mais popular após o isolamento social, o home office e o aumento do tempo que os residentes passam em casa.

Uma das participantes relatou ter ficado assustada ao notar o aumento na produção de resíduos em sua casa, pois antes da pandemia, costumava consumir mais alimentos frescos e durante a pandemia passou a consumir mais industrializados. Outro relato bem interessante, foi que alguns participantes, congelaram seus resíduos para diminuir o número de vezes semanais para levar seu resíduo para Central de Armazenamento de Resíduos (lixeiras compartilhadas).

\section{Produção de resíduos - O macroplástico das embalagens}

O hábito de frequentar comércios alimentícios, sofreu uma mudança com as medidas de isolamento social, muitos dos estabelecimentos passaram a trabalhar com sistemas de entregas conhecidos como delivery e os que já trabalhavam, aprimoraram essa opção, porém esse hábito tende a aumentar a geração de resíduos domiciliares, mas será que as pessoas repararam nisso? Como a pandemia influência no consumo de delivery?

Quando perguntado sobre a frequência de consumo de alimentos via delivery antes e após a pandemia, notou-se um aumento do número de pessoas que não realizam pedidos de alimentos por esse sistema (Figura 3). Antes da pandemia, 39\% dos participantes já não consumiam alimentos desta forma e foi observado um aumento no número de seguidores que não utilizavam este tipo de serviço durante a pandemia, passando para $47 \%$ dos entrevistados. Esse comportamento, segundo os entrevistados, está ligado ao receio de contaminação seja através de embalagens ou de alimentos manipulados por terceiros, ou ainda devido a redução da renda dos entrevistados durante a pandemia. Por outro lado, ao analisar os participantes que costumavam realizar pedidos de pedir alimentos via delivery mais de uma vez na semana, observou-se um aumento, passando de $25 \%$ antes da pandemia para $38 \%$. 
No Brasil, o serviço delivery para alimentos apresentou uma queda no início da pandemia, seguido de um crescimento de mais de $90 \%$ no setor, especialmente devido às medidas de isolamento que fizeram este sistema ser muitas vezes a única fonte de renda dos estabelecimentos (SEBRAE, 2020).

Figura 3 - Pedido de alimento via delivery antes e durante a pandemia, e os tipos de embalagens que chegam na casa das pessoas.
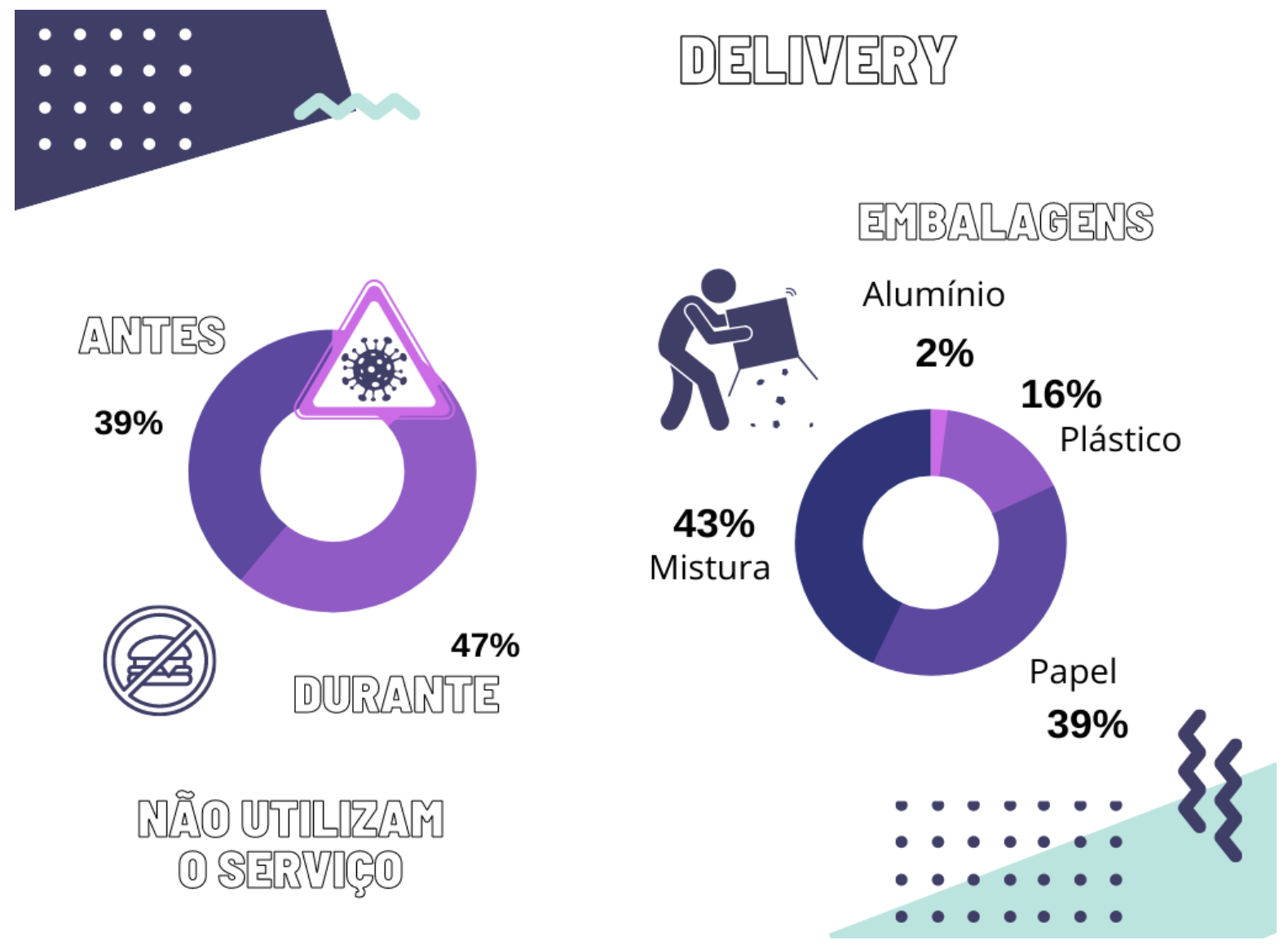

Fonte: Autoria própria (2020).

Em termos de embalagens, $43 \%$ dos entrevistados afirmaram que receberam suas encomendas através de uma mistura de diferentes materiais, como plástico, papel e alumínio, $39 \%$ responderam ser papel, 16\% plástico e somente 2\% alumínio (Figura 3). De acordo com os relatos de alguns participantes, quando sentem vontade de comer algo diferente procuram optar por produtos que sejam embalados em papel, como a pizza por exemplo. Outros participantes relataram que costumavam comer em restaurantes e que mesmo sentindo muita falta, preferem não consumir devido o tipo de embalagem no qual são entregues. Por outro lado, parte dos participantes relatou que se preocupavam com o produto e não se importam com o tipo de embalagem. 
Apesar desses relatos e comportamentos restritos aos entrevistados ligados ao projeto Água Viva, Araujo e Silva (2020) afirmaram que com o isolamento social houve um aumento na geração de resíduos sólidos, especialmente os recicláveis. Esse aumento pode refletir o aumento nos consumos de outros produtos que não apenas relacionados a embalagens pelos pedidos de delivery, mas aumento no consumo de outros produtos embalados que venham dos supermercados e outras fontes. Esses dados também nos levaram ao questionamento sobre o perfil dos entrevistados, seriam estes reflexos da interação com o projeto de extensão?

E ao ir ao mercado, padaria, farmácia ou outros estabelecimentos, será que as pessoas reparam nas embalagens? Será que optam por produtos que não estejam embalados em plástico?

Figura 4 - Escolha entre produtos com ou sem embalagem plástica e uso de sacola plástica durante a pandemia.
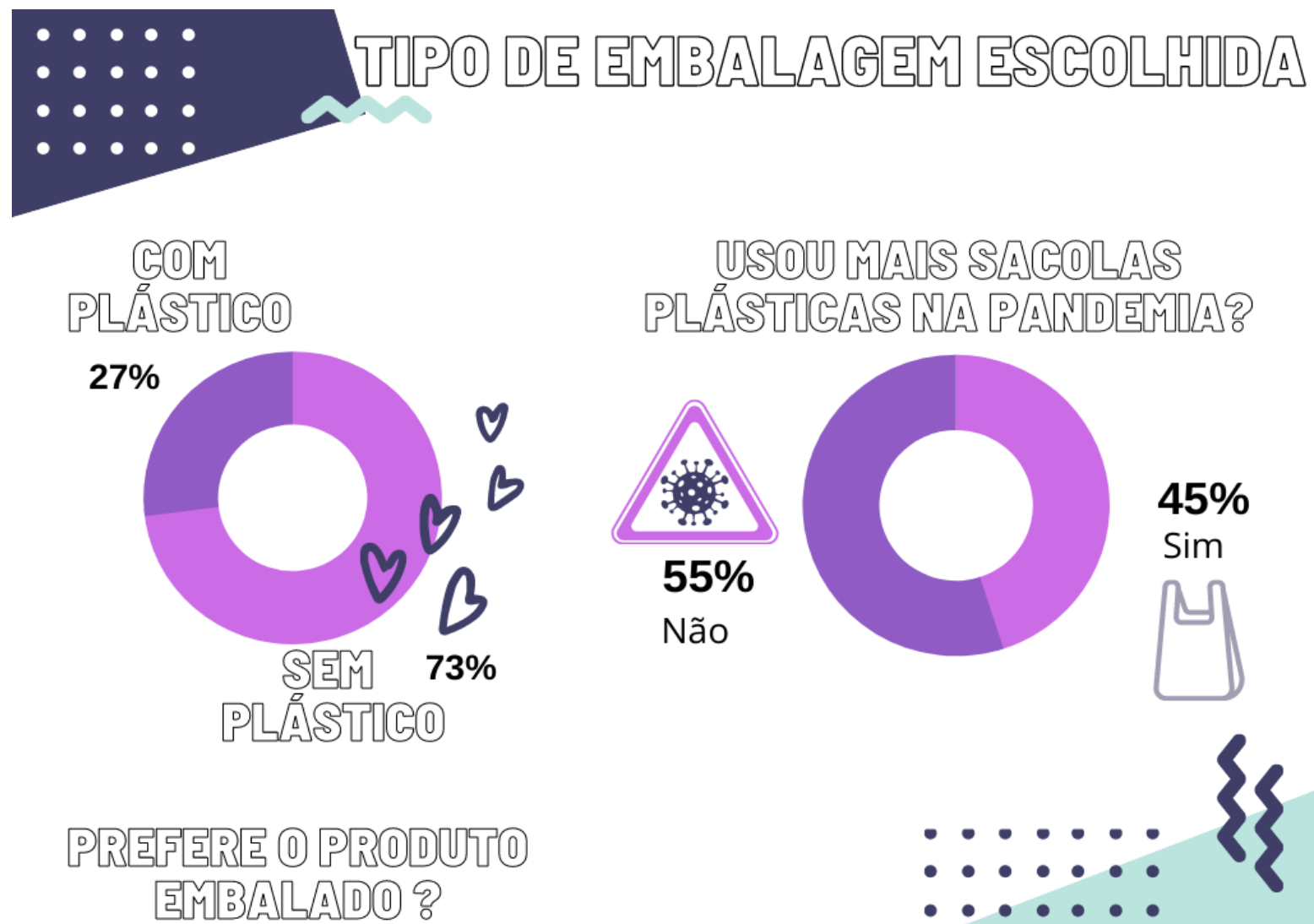

$45 \%$ Sim
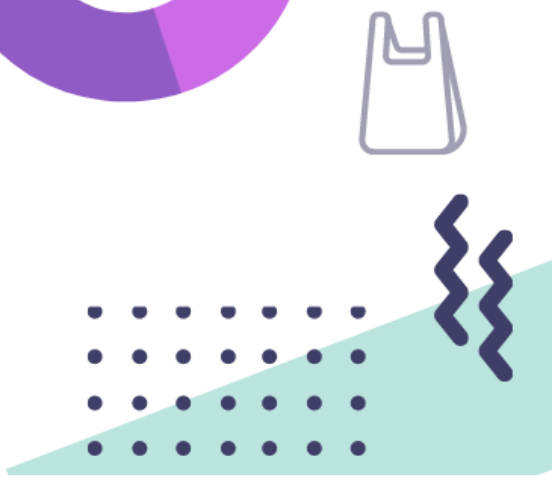

Fonte: Autoria própria (2020).

A grande maioria dos entrevistados $(73 \%)$, responderam que optam por produtos sem embalagem plástica (Figura 4). Os demais entrevistados justificaram que optam pelo produto que tiver o menor preço, não se importando com a embalagem, mas sim com a sua economia e qualidade do que estão comprando. O preço mais elevado de alguns produtos industrializados que são comercializados em embalagens não plásticas é um dos obstáculos encontrados pelos 
consumidores. A possibilidade de confeccionar os mais diferentes artigos e objetos com custo reduzido, torna o plástico mais acessível à população (PIATTI; RODRIGUES, 2005). É importante ressaltar que nesse custo do plástico não são contabilizados os danos ambientais causados por sua larga utilização.

A utilização de produtos de matéria prima renovável é de extrema importância para construção de um futuro mais sustentável. Para que um produto qualquer, possa ser considerável sustentável, deve ser avaliado de diferentes formas, levando em conta questões ambientais, sociais e econômicas. É preciso avaliar quais os possíveis impactos, desde a préprodução até o descarte, o redesign de produtos já existentes, buscando a sustentabilidade, deve estar conectado a tecnologias limpas e que seja aceito social e culturalmente (BRANDÃO, 2007).

Alguns entrevistados optam por produtos que contenham a embalagem plástica, alegando se sentirem mais seguros, principalmente quando relacionado com compra de alimentos, pois sem a embalagem as pessoas tendem a "apalpar" principalmente as frutas, e em épocas de pandemia, esses entrevistados disseram prezar por um produto que tenha sido tocado a menor quantidade de vezes possível. No entanto, o que muitos consumidores não sabem é que o plástico pode também ser um vetor do SARS-CoV-2, já que o mesmo sobrevive em superfícies plásticas (PRATA et al., 2020). Além disso, a própria embalagem pode contaminar os alimentos, por meio da migração de substâncias químicas provenientes das embalagens plásticas, alterando as características sensoriais dos produtos e expondo o consumidor à substâncias com potencial tóxico (ARVANITOYANNIS; BOSNEA, 2004).

\section{Produção de resíduos - Higiene pessoal e o microplástico}

Com o intuito de diminuir a propagação do SARS-CoV-2, medidas isolamento social, reforço nas medidas de higienização e o uso de máscaras faciais são incentivadas em diversos países (ARAGAW, 2020) até que o modo de transmissão de SARS-CoV-2 seja totalmente compreendido ou a sua transmissão seja controlada, à exemplo do que foi adotado no cenário de pandemia de influenza (SCHUCHAT; BELL; REDD, 2011). De fato, a utilização das máscaras passou a ser fundamental e muitas vezes obrigatória em diversas nações.

Figura 5 - Preferência entre uso de máscara reutilizável ou descartável durante a pandemia. 


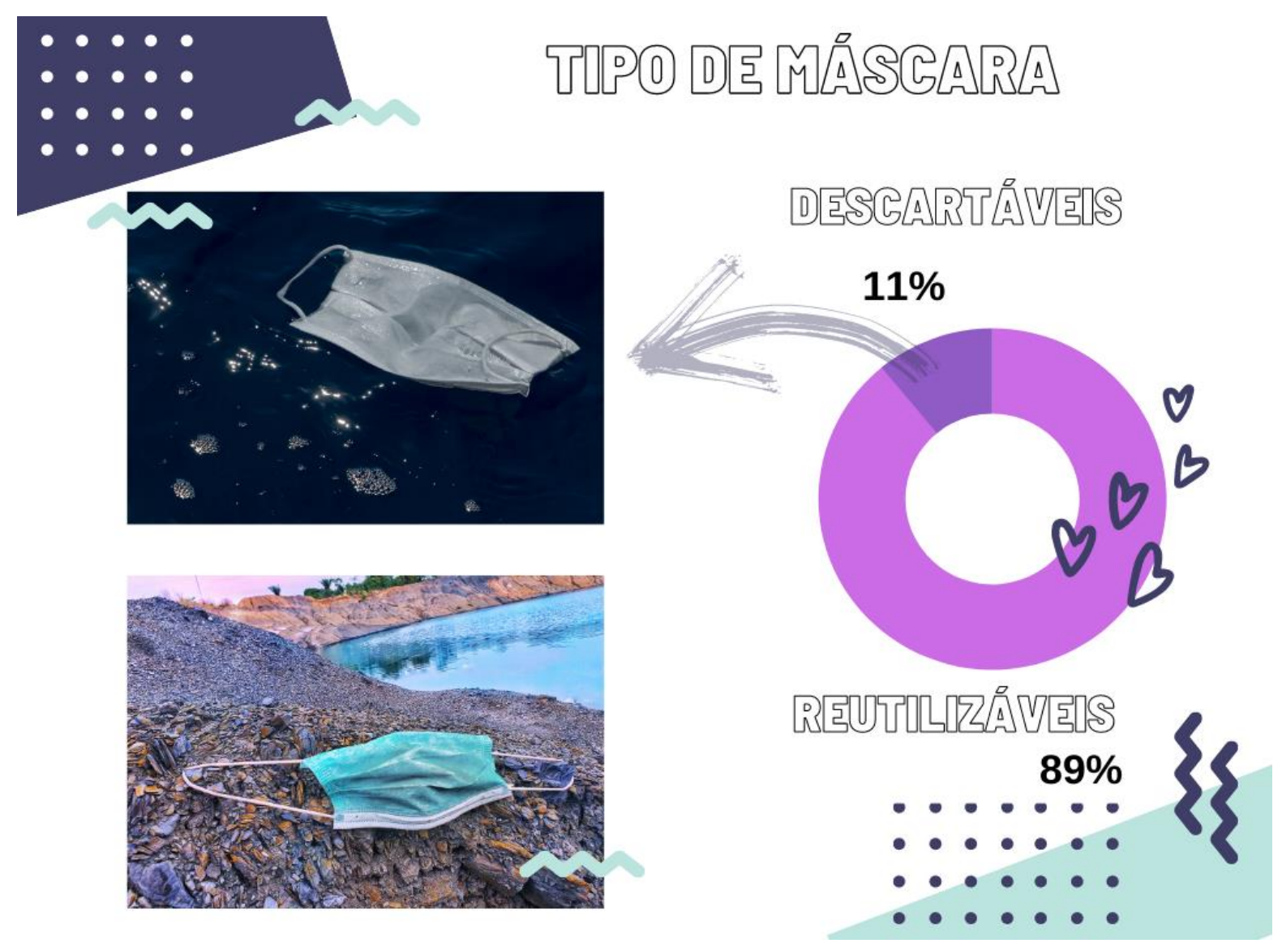

Fonte: Compilação do autor (2020).

Quando perguntado sobre a preferência dos participantes sobre o uso entre máscaras descartáveis ou reutilizáveis durante a pandemia, 89\% responderam que optam por utilizarem máscaras reutilizáveis, enquanto 11\% utilizam máscaras descartáveis (Figura 5).

Um relato da participante da Austrália mencionou que não utilizou máscaras, uma vez que no local que reside foram implementadas outras técnicas de contenção e propagação da doença. Por outro lado, diversos locais do mundo relatam o descarte incorreto das máscaras, registrando inclusive a presença das mesmas no oceano (BOYLE, 2020). Durante uma recente viagem de pesquisa às ilhas de Soko, a equipe da OceansAsia, encontrou uma grande quantidade de máscaras cirúrgicas em águas próximas à costa (OceansAsia, 2020). O descarte massivo de máscaras faciais dá evidências sobre a desordem ambiental tanto no ambiente terrestre quanto aquático e que a pandemia global não reduziu a poluição do plástico no meio ambiente (ARAGAW, 2020).

A pandemia fez com que os hábitos de higiene pessoal fossem reavaliados e reforçados. Não apenas o consumo de água aumentou (COOPER, 2020) mas também a produção de efluentes domésticos que podem carregar consigo microplásticos. Utiliza-se plástico em 
diversos produtos de higiene pessoal, seja na embalagem ou fazendo parte da formulação do produto (Figura 6).

Estima-se que a cada ano são descartadas em torno de 4 escovas de dente por pessoa, pensando globalmente, isso é assustador. A utilização de escovas de dente de plástico pode gerar diversos problemas ambientais, já que além do descarte ser muitas vezes feito de forma incorreta, podem demorar mais de 400 anos para se decompor (LESSA, 2019). Dentre os 215 entrevistados, 92\% afirmam utilizar escovas de dente de plástico, enquanto apenas $8 \%$ opta por escovas de fontes renováveis como as de bambu. A utilização do bambu exemplifica o uso de matéria prima renovável e de fato biodegradável, com diversas possibilidades de uso, rápido crescimento, fácil adaptação em diferentes territórios brasileiros, além da capacidade de geração de empregos que promove a inclusão social, importantíssima para o desenvolvimento sustentável na sociedade (PEREIRA, 2012).

Figura 6 - Uso de esfoliantes e sua composição e tipo de escova dental preferida.

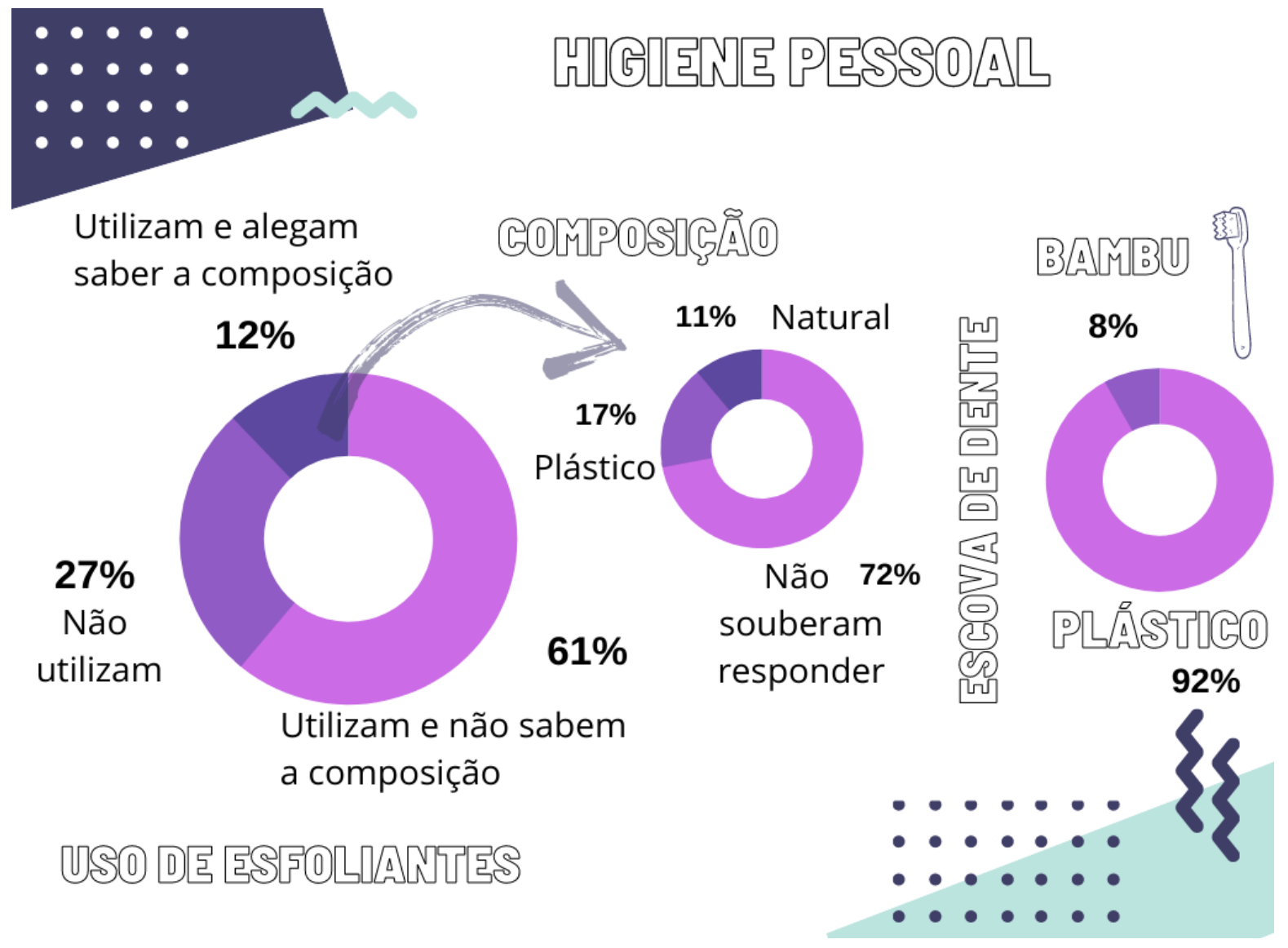

Fonte: Autoria própria (2020).

Nos produtos de higiene pessoal esconde-se o uso de plástico em produtos como creme dental, cremes e sabonetes. Dos entrevistados, $34 \%$ relatou fazer uso de sabonetes esfoliantes, 
$21 \%$ utilizam cremes com partículas esfoliantes e $28 \%$ optam por creme dental com microesferas branqueadoras.

Quando questionados a respeito da composição dessas partículas esfoliantes, 63\% dos entrevistados não souberam a composição dos produtos que utilizam. Dos $12 \%$ que afirmaram saber a composição dos esfoliantes, metade (52\%) informou que a composição é plástica. As microesferas esfoliantes correspondem à um grupo de partículas plásticas produzidas em tamanhos que variam de $10 \mu \mathrm{m}$ a $1 \mathrm{~mm}$ e justamente por serem tão pequenas são também tão perigosas (ROCHA-SANTOS; DUARTE, 2017), pois são de fácil dispersão e difícil remoção no meio (FERRARI, 2019). Além disso, durante a utilização de cremes dentais com essas partículas por exemplo, parte acaba sendo ingerida acidentalmente e através dessas ingestões acidentais e outras, o ser humano pode estar consumindo 5 gramas de plástico por semana, o equivalente a 5 garrafas por ano (PALANISAMI; SENATHIRAJAH, 2019). Essas micropartículas presentes nos cosméticos contribuem de forma significativa para o acúmulo de plásticos nos ambientes, em especial nos oceanos (FENDALL; SEWELL, 2009).

A falta da compreensão dos consumidores em relação aos impactos negativos no ambiente e danos à saúde humana, aliados às informações com nomes quase indecifráveis contidas nos rótulos dos produtos, fazem com que estes continuem tendo mercado (HOFFMANN, 2019). Se estes fatos são assustadores, a mudança de hábitos traz esperança. Um relato enviado por uma profissional da área da estética revelou a utilização diária de esfoliantes durante seus atendimentos, porém após informações adquiridas através do projeto Água Viva sobre a composição dos mesmos, ela substituiu seus produtos por esfoliantes com composição natural.

Outros pequenos perigosos são as microfibras plásticas que são desprendidas durante o processo convencional de lavagem de tecidos sintéticos (HARTLINE et al., 2016) estão presentes em roupas e até mesmo em máscaras quando feitas de tecidos que contém poliéster, polietileno e outros polímeros sintéticos. Estima-se que em cada lavagem centenas de microfibras plásticas sejam liberadas (HARTLINE et al., 2016).

A higienização de roupas e máscaras reutilizáveis deve ocorrer a cada situação de possível exposição, durante o período da pandemia. Mas, será que estamos aumentando a disponibilização de microfibras plásticas para o ambiente? Com este intuito questionamos também os entrevistados sobre a frequência de lavagem de roupa, se este hábito passou a ser mais frequente bem como se estão cientes da composição das mesmas. 
Figura 7 - Frequência da lavagem de roupas semanal, sua mudança na pandemia e composição das roupas utilizadas.

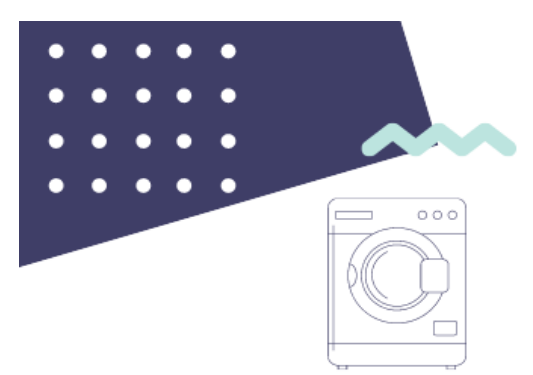

2 vezes

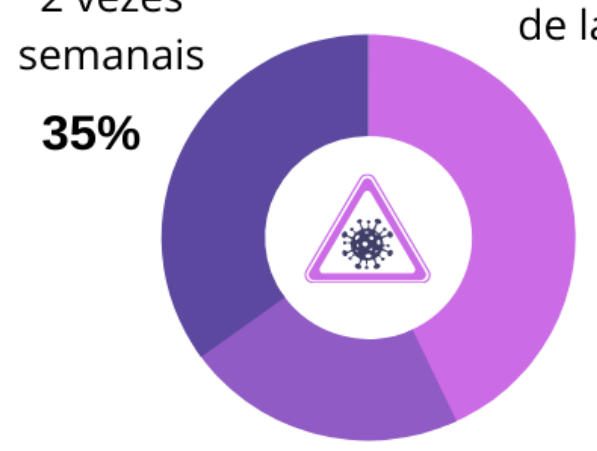

Semanalmente $22 \%$

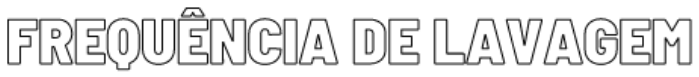

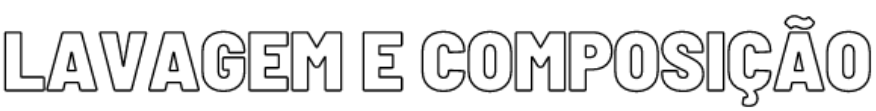
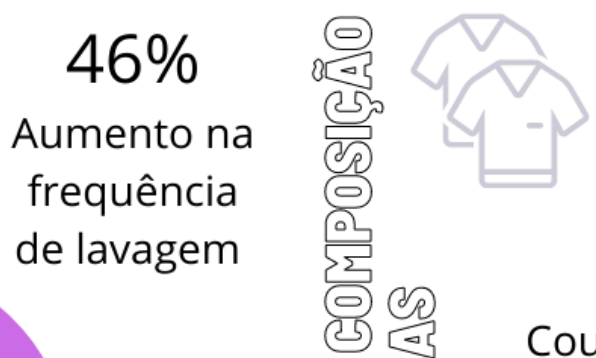

$65 \%$

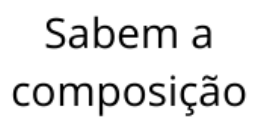

$43 \%$

3 vezes

ou mais
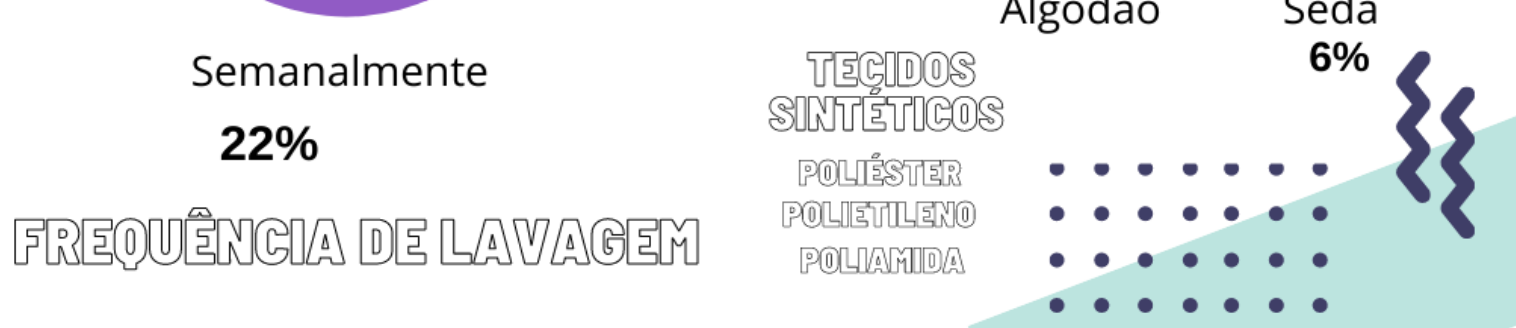

Fonte: Autoria própria (2020).

Houve um aumento na frequência de lavagem de roupas para $46 \%$ dos entrevistados, sendo que $43 \%$ lavam as roupas três ou mais vezes durante a semana (Figura 7), em termos de conhecimento sobre a composição de suas roupas, $65 \%$ alegaram saber as roupas que aparecem com mais frequência, sendo aquelas que possuem algodão em sua composição (50\%), em seguida aparecem os tecidos sintéticos tais como poliéster, polietileno, poliamida e até mesmo PET (37\%), materiais como couro e seda compõem menos de $6 \%$.

\section{Mudar é possível?}

Se você soubesse que seus hábitos são prejudiciais ao meio ambiente, você estaria disposto a mudar? Segundo os participantes sim. Estão dispostos $99 \%$ dos entrevistados, estes relataram que estão buscando melhorar o seu conhecimento e sua atitude em relação ao consumismo e ao meio ambiente e que iniciaram essa jornada através da busca por informações simples, diretas e acessadas na maior parte virtualmente. Apenas dois entrevistados responderam não. Segundo os mesmos, com a correria do dia a dia, o trabalho, as 
responsabilidades, prazos e o baixo orçamento, essas questões acabam ficando fora de cogitação por considerarem não práticas e caras.

A produção e consumo de diferentes produtos, continuam causando impactos negativos imensuráveis ao meio ambiente. Pode-se observar parte da sociedade atual passou a buscar por alternativas para uma vida mais sustentável. Nesse cenário, a educação ambiental desempenha um papel fundamental formando indivíduos mais preocupados com questões e problemas ambientais, buscando a preservação da natureza (FREIRE, 2007). E é dessa forma que o projeto Água Viva contribui para a popularização das problemáticas ambientais. O objetivo do projeto vai além de informar, tem como intuito provocar, engajar e encorajar mudanças individuais e coletivas.

Assim como Singer (1993), acredita-se que ao se tomar uma atitude ética e sustentável, sinais são enviados para quem estiver ao redor, e assim o movimento se propaga e cria não só exemplo, mas forma opinião.

Cada pequena atitude importa, elas têm o potencial de mudar o mercado e através da colaboração de serviços públicos, indústrias, corporações, formuladores de políticas, líderes governamentais e especialistas, pode-se decretar mudanças a nível de sistema. As partes interessadas devem se reunir para criar diretrizes rígidas para a criação de produtos reutilizáveis, recicláveis, higiênicos, de baixo custo e sustentáveis (MINCER, 2020). Desta forma, garantirse-á acessibilidade para todos, resolvendo as dificuldades encontradas e relatadas pelos participantes ao realizar mudanças sustentáveis como no caso o preço e os obstáculos em se encontrar certos produtos.

O trabalho realizado no projeto de extensão Água Viva: Do Recurso ao Patrimônio da Universidade do Vale do Itajaí, tem mostrado resultados positivos. O público alvo que nos acompanha nas redes sociais têm demonstrado que esta interação com o conteúdo publicado é informativa, reflexiva e com um grande potencial de ação, mesmo frente a este novo modo de viver e fazer. Após responder o questionário, diversos entrevistados buscaram dialogar com a página do projeto Água Viva para compreender melhor como algumas mudanças poderiam ser feitas, com base em suas respostas. As redes sociais possibilitaram a ampliação na rede de comunicação do projeto, alcançando pessoas com diferentes realidades socioambientais. 


\section{REFERÊNCIAS}

ABRELPE. Panorama dos resíduos sólidos no Brasil. 2019. Disponível em: https://abrelpe.org.br/panorama/. Acesso em: 02 jul. 2020.

ABRELPE. Produção de lixo domiciliar durante pandemia. 2020. Disponível em: http://abrelpe.org.br/recomendacoes-para-a-gestao-de-residuos-solidos-durante-a-pandemiade-coronavirus-covid-19/. Acesso em: 02 jul. 2020.

ANDREOLI, Cleverson V. et al. Resíduos Sólidos: Origem, classificação e soluções para destinação final adequada. Complexidade: Redes e Conexões do Ser Sustentável. 1ª ed, 2014.

ARAGAW, Tadele Assefa. Surgical face masks as a potential source for microplastic pollution in the COVID-19 scenario. Marine Pollution Bulletin, p. 111517, 2020.

ARAUJO, Elaine Cristina dos Santos; SILVA, Viviane Farias. A gestão de resíduos sólidos em época de pandemia do Covid-19. GeoGraphos, vol. 11, n 129 p. 192-215, 2020.

ARVANITOYANNIS, Ioannis S.; BOSNEA, Loulouda. Migration of substances from food packaging materials to foods. Critical reviews in food science and nutrition, v. 44, n. 2, p. 63-76, 2004.

BARDIN, Laurence. Análise de Conteúdo. São Paulo: Almedina Brasil, 2016. 279 p.

BOYLE, Louise. Discarded coronavirus face masks and gloves rising threat to ocean life, conservationists warn. Independent. 2020.

BRANDÃO, Marili de Lima Ferreira. Design sustentável: O uso da matéria prima renovável: um estudo de caso da produção do couro vegetal no norte do brasil. 2007. $134 \mathrm{f}$. Dissertação (Mestrado) - Curso de Arquitetura e Urbanismo, Universidade de São Paulo, São Paulo, 2007. Disponível em: https://www.teses.usp.br/teses/disponiveis/16/16134/tde28052010-150924/publico/tese.pdf. Acesso em: 22 ago. 2020. 
CALIMAN FILADELFI, Ana Maria et al. Uso da web e da pesquisa na educação como prática extensionista. Revista Ciência em Extensão, v. 15, n. 2, 2019. Disponível em: https://web.a.ebscohost.com/ehost/pdfviewer/pdfviewer?vid=1\&sid=f8cc5c8b-e252-41b5a2e4-aed4c585dc67\%40sessionmgr4008. Acesso em: 06/08/2020.

COOPER, Rachel. Water security beyond Covid-19. K4D - Knowledge, evidence and learning for development. p. 1 -24, 2020.

FAGUNDES, Lena Marques; MISSIO, Eloir. Resíduos plásticos nos oceanos: ameaça à fauna marinha. Brazilian journal Of Development, Curitiba, v. 5, n. 3, p. 2396-2401, mar. 2019. Disponível em: https://www.brazilianjournals.com/index.php/BRJD/article/view/1287/1162. Acesso em: 08 ago. 2020

FENDALL, Lisa S.; SEWELL, Mary A. Contributing to marine pollution by washing your face: microplastics in facial cleansers. Marine pollution bulletin, v. 58, n. 8, p. 1225-1228, 2009.

FERRARI, Matheus Feza. Avaliação da presença de microplásticos em esgoto sanitário do município de Campo Mourão - PR. 2019. Trabalho de Conclusão de Curso (Bacharelado em Engenharia Ambiental) - Universidade Tecnológica Federal do Paraná, Campo Mourão, 2019.

FREIRE, Ana Maria. Educação para a sustentabilidade: implicações para o currículo escolar e para a formação de professores. Pesquisa em Educação Ambiental, São Paulo, v. 2, n. 1, p. 141-154, 2007.

GRZEBIELUKA, Douglas; KUBIAK, Izete; SCHILLER, Adriane Monteiro. Educação Ambiental: A importância deste debate na Educação Infantil. Revista Monografias Ambientais, v. 13, n. 5, p. 3881-3906, 2014.

HARTLINE, Niko L. et al. Microfiber masses recovered from conventional machine washing of new or aged garments. Environmental science \& technology, v. 50, n. 21, p. 11532-11538, 2016.

HOFFMANN, Simone. Decos - Interface funcional para aplicativo de descrição de componentes de produtos cosméticos... TCC (Graduação) - Curso de Design de Moda, 
Universidade Federal de Santa Catarina, Florianópolis, p.72, .2019. Disponível em: https://repositorio.ufsc.br/handle/123456789/197248. Acesso em: 14 ago. 2020.

HOORNWEG, Daniel; BHADA-TATA, Perinaz. What a waste: a global review of solid waste management. 2012. Disponível em: http://documents.worldbank.org/curated/en/302341468126264791/What-a-waste-a-globalreview-of-solid-waste-management. Acesso em: 12 ago.2020.

LESSA, Ângelo. Chega de plástico: 101 maneiras de se livrar do plástico e salvar o planeta. Editora sextante.p. 128 , 2019 MINCER, Jacqueline. Aftershocks of SARS-CoV-2: A plastic pandemic. A plastic pandemic. 2020. Disponível em: https://www.cfp.ca/news/2020/08/17/08-17. Acesso em: 04 jul. 2020.

NEHER, Richard A. et al. Impact of seasonal forcing on a potential SARS-CoV-2 pandemic. MedRxiv, 2020. Disponível em: https://www.medrxiv.org/content/medrxiv/early/2020/02/17/2020.02.13.20022806.full.pdf. Acesso em: 11 ago.2020.

NUNES, Ana Lucia de Paula Ferreira; DA CRUZ SILVA, Maria Batista. A extensão universitária no ensino superior e a sociedade. Mal-Estar e Sociedade, v. 4, n. 7, p. 119-133, 2011.

NZEADIBE, Thaddeus Chidi; EJIKE-ALIEJI, Adaeze U.P. Solid waste management during Covid-19 pandemic: Policy gaps and prospects for inclusive waste governance in Nigeria. Local Environment, v. 25, n. 7, p. 527-535, 2020.

OCEANSASIA. No shortage of surgical masks at the beach. 2020. Disponível em: http://oceansasia.org/beach-mask-coronavirus/. Acesso em: 14 ago. 2020.

ONU, Organização das Nações Unidas. Coronavirus disease (COVID-19): situation report199. 2020. Disponível em: https://www.who.int/docs/default-source/coronaviruse/situationreports/20200806-covid-19-sitrep-199.pdf?sfvrsn=6b9d262d_2. Acesso em: 07 ago. 2020. 
PEREIRA, Marco Antonio dos Reis. Projeto bambu: introdução de espécies, manejo, caracterização e aplicações. . Tese (livre-docência) - Universidade Estadual Paulista, Faculdade de Engenharia, p.200, 2012. Disponível em: https://repositorio.unesp.br/bitstream/handle/11449/106710/pereira_mar_ld_bauru.pdf?sequen ce=1\&isAllowed=y. Acesso em: 23 ago. 2020.

PIATTI, Tania Maria; RODRIGUES, Reinaldo Augusto Ferreira. Plásticos: características, usos, produção e impactos ambientais. Maceió: Edufal, p. 51, 2005.

ROCHA-SANTOS, Teresa A. P; DUARTE, Armando C. Comprehensive Analytical Chemistry: Characterization and Analysis of Microplastics. Volume 75, Elsevier, 2017.

PRATA, Joana C. SILVA, Ana, L.P. WALKER, Tony R. DUARTE, Armando C. ROCHASANTOS, Teresa.COVID-19 pandemic repercussions on the use and management of plastics. Environmental Science \& Technology, v. 54, n. 13, p. 7760-7765, 2020.

PRAKASH, S.; SRIVASTAVA, S. Covid-19: Environmental and Social Changes during Lockdown. IRE Journals, v. 3(11), 2020. Disponível em: https://irejournals.com/formatedpaper/1702328.pdf. Acesso em 11 ago. 2020.

PRAKASH, S. (2020). Impact of Climate change on human: an overview. Environment and Society , ISBN:978-81-931262-3-3: p64-68.

SEBRAE, Serviço Brasileiro de Apoio às Micro e Pequenas Empresas. Delivery cresce e se torna oportunidade para setor de alimentação. 2020. Disponível em: https://www.sebrae.com.br/sites/PortalSebrae/sebraeaz/delivery-cresce-e-se-tornaoportunidade-para-setor-dealimentacao,8bf8d28f48081710VgnVCM1000004c00210aRCRD. Acesso em: 17 nov. 2020.

SENATHIRAJAH, Kala; PALANISAMI, Thava. How Much Microplastics Are We Ingesting?: Estimation of the Mass of Microplastics Ingested. 2019. Universidade de NewCastle, Austrália. Disponível em: https://www.newcastle.edu.au/newsroom/featured/plastic-ingestion-by-people-could-be- 
equating-to-a-credit-card-a-week/how-much-microplastics-are-we-ingesting-estimation-ofthe-mass-of-microplastics-ingested. Acesso em: 26 ago. 2020.

SCHUCHAT, Anne; BELL, Beth; REDD, Stephen. The science behind preparing and responding to pandemic influenza: the lessons and limits of science. Clinical Infectious Diseases, v. 52, n. suppl_1, p. S8-S12, 2011.

SINGER, Peter. Taking Life: Humans. In: SINGER, Peter. Practical Ethics. 2. ed. Cambridge: Cambridge University Press, 1993. cap.7 ,p. 206-207.

UNEP, United Nations Environment Programme. This World Environment Day, it's time for a change. 2018. Disponível em: https://www.unenvironment.org/interactive/beat-plasticpollution/. Acesso em 14 ago. 2020.

Recebido em: 12 de Agosto de 2020. Aceito em: 30 de Março de 2021. 